\title{
Characterization of an autostimulatory substance produced by Escherichia coli
}

\author{
Dieter H. Weichart $†$ and Douglas B. Kell
}

Institute of Biological Sciences, Cledwyn Building, University of Wales, Aberystwyth SY23 3DD, UK
Author for correspondence: Douglas B. Kell. Tel: +44 1970 622334. Fax: +44 1970622354. e-mail:dbk@aber.ac.uk

\begin{abstract}
The recovery of dilute populations of stationary phase cells of Escherichia coli was studied using an automatic growth analyser. The addition of $30 \%$ supernatant from 2-d-old stationary phase cells of the organism reproducibly shortened the apparent lag times by $22-57.5 \%$, depending on the age of the inoculum. True lag times, as determined by colony counts, of stationary phase cells were reduced by supernatant addition by 41-62\%. The growthstimulating substance was characterized and partly purified from supernatants: the active material was shown to be dialysable, heat-stable, acid- and alkali-stable and protease-resistant. Extraction with ethyl acetate or ion-exchange resins was not successful, but the active material could be quantitatively extracted with ethanol after saturation with salt. It is concluded that the active substance is a small, non-proteinaceous, non-ionic organic molecule. Separation of extracts by HPLC indicated that the stimulatory substance is weakly hydrophobic and has retention times similar to those of uracil. So far, however, the exact chemical identity of the active substance has not been elucidated.
\end{abstract}

Keywords: intercellular signalling, lag phase, growth stimulation

\section{INTRODUCTION}

Bacterial populations are capable of cooperation and coordination of their activities to an extent which reminds one of the behaviour of multicellular organisms (Shapiro, 1998). Recently, the role of intercellular communication in the regulation of these social phenomena has received widespread attention, and a variety of diffusible chemical signals involved in communication has been discovered. The phenotypes regulated by intercellular communication include luminescence, gene transfer, sporulation, swarming, fruiting body formation and the production of siderophores, exoenzymes and other virulence factors, as well as the synthesis of antibiotics and other secondary metabolites. The chemical nature of the signals affording these types of communication depends on the organism and phenotype studied; in some cases they are highly speciesspecific, and are thus considered 'pheromones'. Bacterial pheromones described so far include peptides, nucleotides, acylated homoserine lactones, amino acids, fatty acids, cyclic dipeptides, a quinolone and a ketone

†Present address: Institut für Biologie-Mikrobiologie, Königin Luise Straße 12-16, D-14195 Berlin, Germany.
(Fuqua \& Greenberg, 1998; Fuqua et al., 1996; Holden et al., 1999; Hull et al., 1998; Kaiser \& Losick, 1993; Kell et al., 1995; Pesci et al., 1999; Salmond et al., 1995; Swift et al., 1996). In certain Gram-positive organisms, intercellular growth stimulation mediated by proteinaceous cytokines has also recently been demonstrated (Kaprelyants et al., 1999; Kell \& Young, 2000; Mukamolova et al., 1998a).

In Escherichia coli, no signalling molecule with a defined role has been chemically identified so far to our knowledge, although several papers have reported the action of such substances. Induction of certain E. coli genes by the addition of supernatant has been described (Baca-DeLancey et al., 1999; Li et al., 1997), and growthinhibiting effects of supernatants have been reported in E. coli and other organisms (Barrow et al., 1996; Gray et al., 1996; Srinivasan et al., 1998). So far, however, the substances involved in these processes have not been identified. While homoserine lactone derivatives were shown to have growth-inhibiting effects by several authors (Garcia-Lara et al., 1996; Sitnikov et al., 1996; Surette \& Bassler, 1998; Surette et al., 1999; Withers \& Nordström, 1998), the production of these molecules by E. coli has not been demonstrated. On the other hand, published accounts of cases in which E. coli 
supernatants stimulate growth, survival and activity of the producing strain appear to be rare. The only case known to us involves the autoinducer-mediated stimulation of the growth of a variety of Gram-negative organisms in serum-containing media by exogenously supplied noradrenaline (norepinephrine), as described by Lyte, Williams and colleagues (e.g. Freestone et al., 2000; Lyte et al., 1996). This, however, might not be considered a pure case of autostimulation because of the involvement of the eukaryotic hormone.

It is of course a common observation that low inocula lead to extremely long lag times unless the cells are supplied with 'spent medium' (also called 'conditioned medium' or 'culture filtrate'; Lodge \& Hinshelwood, 1943). Investigations of the physiological or chemical basis of this kind of effect are, however, rarely found in the literature. Ajl \& Werkman (1948) reported stimulation of $E$. coli by $\mathrm{CO}_{2}$ which potentially accumulates in spent medium (cf. Dixon \& Kell, 1989; Neidhardt et al., 1974). We here describe an autostimulatory effect of E. coli supernatants which is independent of the requirement for $\mathrm{CO}_{2}$ and which to our knowledge has not been characterized before.

\section{METHODS}

Bacterial strains and maintenance. Escherichia coli ZK126 [W3110 slacU169 tna2 (Connell et al., 1987), received from R. Kolter, Harvard Medical School] was used throughout this study as the model strain. By using other E. coli strains [ATCC 25922, and ZK1000 (ZK126 rpoS::kan, R. Kolter)], it was ascertained that the observed effects are not strain-specific. All strains were maintained on LB agar plates.

Chemicals. All chemicals used were analytical grade and obtained from Sigma, except for cAMP, which was obtained from Boehringer, and N-hexanoylhomoserine lactone (HHL) and butyrylhomoserine lactone (BHL), which were a gift from Dr Michael Givskov (Technical University of Denmark, Lyngby, Denmark). HPLC grade solvents were purchased from Fisher Scientific.

Growth conditions and media. All cultures were inoculated from 2-d-old single colonies on LB plates into MM medium [MOPS-buffered minimal medium (Neidhardt et al., 1974), see below]. The cultures were grown at $37^{\circ} \mathrm{C}$ with orbital shaking for $20 \mathrm{~h}$, diluted 1:200 in fresh MM medium, grown for another $20 \mathrm{~h}$, and finally diluted once again 1:200 in fresh MM medium. This method ensures that the carry-over of material from the LB-grown colonies (which might contain growth factors such as those found in LB) was reduced to negligible amounts (less than a proportion of $3 \times 10^{-6} \%, \mathrm{v} / \mathrm{v}$, if a maximum of $2 \mu \mathrm{l}$ of initial inoculate is assumed for cultures of $2 \mathrm{ml}$ ). At the same time this way both the homogeneity and the reproducibility of the physiology of cells in the final culture were ascertained.

Medium MM was mixed freshly on the day of experiments from the following three stock solutions: $44 \mathrm{ml} 1.5 \mathrm{mM}$ $\mathrm{K}_{2} \mathrm{HPO}_{4}, 5 \mathrm{ml}$ sterile filtered ' $10 \times$ MOPS' (see below, stored frozen at $-20^{\circ} \mathrm{C}$ ), and $0.75 \mathrm{ml}$ sterile filtered $0.67 \mathrm{M}$ $\mathrm{NaHCO}_{3}$ (final concentration: $10 \mathrm{mM}$ ). Appropriate carbon sources were added at the concentrations indicated: glucose or succinate were added from sterile filtered stock solutions of $10 \%(\mathrm{w} / \mathrm{v}$ ) (final concentrations: $0 \cdot 001-0 \cdot 05 \%, \mathrm{w} / \mathrm{v}$ ), and glycerol was added from autoclaved stock solutions.
' $10 \times$ MOPS' is a $10 \times$ stock of buffer substances and salts containing $400 \mathrm{ml} 1 \mathrm{M}$ MOPS (pH 7.4), $40 \mathrm{ml} 1 \mathrm{M}$ Tricine (pH 7.8), $10 \mathrm{ml} 10 \mathrm{mM} \mathrm{FeSO}_{4}, 50 \mathrm{ml} 1.9 \mathrm{M} \mathrm{NH}_{4} \mathrm{Cl}, 10 \mathrm{ml}$ $0.276 \mathrm{M} \mathrm{K}_{2} \mathrm{SO}_{4}, 5 \mathrm{ml} 0.5 \mathrm{mM} \mathrm{CaCl}, 5 \mathrm{ml} \mathrm{0.528} \mathrm{M} \mathrm{MgCl}_{2}$, $100 \mathrm{ml} 5 \mathrm{M} \mathrm{NaCl}, 10 \mathrm{ml}$ 'MNS' (Micro-Nutrient-Solution, see below) and $370 \mathrm{ml} \mathrm{H} \mathrm{H}_{2} \mathrm{O}$ to give $1000 \mathrm{ml}$. 'MNS' contained $10 \mu \mathrm{M} \mathrm{ZnSO}_{4}, 80 \mu \mathrm{M} \mathrm{MnCl}_{2}, 10 \mu \mathrm{M} \mathrm{CuSO}_{4}, 30 \mu \mathrm{M} \mathrm{CoCl}_{2}$, $0.4 \mathrm{mM} \mathrm{H}_{3} \mathrm{BO}_{4}$ and $3 \mu \mathrm{M}\left(\mathrm{NH}_{4}\right)_{6}\left(\mathrm{Mo}_{7}\right)_{24}$. Final concentrations of $\mathrm{MOPS}, \mathrm{NaHCO}_{3}$ and all inorganic constituents of $\mathrm{MM}$ medium are identical to those published by Neidhardt et al. (1974).

Vitamins were tested at the following concentrations $\left(1^{-1}\right)$ : $50 \mu \mathrm{g}$ riboflavin, nicotinamide and D-pantothenic acid; $20 \mu \mathrm{g}$ para-aminobenzoic acid, folic acid and D-biotin; $15 \mu \mathrm{g}$ pyridoxine; $10 \mu \mathrm{g}$ pyridoxal. $\mathrm{HCl}$ and DL-6,8-thioctic acid; $5 \mu \mathrm{g}$ pyridoxamine; $2 \mu \mathrm{g}$ cyanocobalamine; and $0.03 \mu \mathrm{l}$ tocopherol. This combination of vitamins is considered complete (Cote $\&$ Gherna, 1994) and is referred to as ' 12 vitamins' in Results. In addition, thiamin was tested at concentrations of $2,4,10,25$, 50 and $200 \mu \mathrm{g} \mathrm{l}^{-1}$.

Preparation of supernatants and testing of effects on growth. Supernatants from exponentially growing or stationary phase cells were prepared in the following fashion. The cells were grown in MM medium containing $0.04 \%$ (w/v) glucose (unless stated otherwise) with shaking at $37^{\circ} \mathrm{C}$, harvested by centrifugation $\left(20^{\circ} \mathrm{C}, 12000 \mathrm{~g}, 10 \mathrm{~min}\right)$, and the supernatants were sterile filtered twice $(0.2 \mu \mathrm{m}$; Sartorius). The sterile filters were always washed with at least $40 \mathrm{ml}$ HPLC grade water immediately prior to using them to filter supernatants or any other solutions to reduce the possibility of substances being released from the filter cartridges into the filtrates. The filtered supernatants were frozen at $-20^{\circ} \mathrm{C}$ until they were processed. The activity of supernatants of cells grown in vessels of different materials and sizes was tested, but no difference in activity was found between cultures grown in plastic screw cap tubes $(50 \mathrm{ml}$ total volume, holding $5 \mathrm{ml}$ cultures) or in different sizes of glass Erlenmeyer flasks (up to 11 culture in flasks of 31 total volume). For production of supernatants of cells that were limited due to depletion of carbon, cultures were kept at $37^{\circ} \mathrm{C}$ with shaking after growth in MM medium with $0.04 \%(\mathrm{w} / \mathrm{v})$ glucose, and harvested at the times indicated. For supernatants of cells that were carbonlimited after resuspension in medium lacking carbon source, the cells were grown in MM medium containing $0 \cdot 8 \%(\mathrm{w} / \mathrm{v})$ glucose, harvested in exponential phase at $3 \cdot 1 \times 10^{8}$ c.f.u. $\mathrm{ml}^{-1}$, and resuspended in MM medium without glucose.

To test the recovery of cells in different growth phases, populations of bacteria were grown in MM medium containing $0.04 \%(\mathrm{w} / \mathrm{v})$ glucose (or $0.05 \%, \mathrm{w} / \mathrm{v}$, glycerol or succinate) under the same conditions, and left at $37^{\circ} \mathrm{C}$ with shaking. At the time of experiment, the populations were diluted in fresh MM medium to a final cell density of 100-500 c.f.u. $\mathrm{ml}^{-1}$, volumes of $200 \mu \mathrm{l}$ each were dispensed into prewarmed 100-well plates, and growth was recorded as turbidity using an automatic growth analyser (BioScreen, Labsystems). The growth analyser was set to a temperature of $37^{\circ} \mathrm{C}$ and shaking to periods of $20 \mathrm{~s}$ of maximum intensity $\min ^{-1}$. Optical density $\left(\mathrm{OD}_{590}\right)$ was monitored every minute with the wavelength at the 'wide band' setting. Apparent lag phases and growth rates were estimated by curve fitting of the $\mathrm{OD}_{590}$ data, using a three-phase fitting programme: the first phase (lag phase) was fitted to $y=y_{0}$; the second (growth) phase to $y=y_{0} \exp (g(t-\operatorname{lag}))$; the third (stationary) phase was fitted to $y=y_{\max }$. The parameters are $y_{0}=$ initial OD, $t=$ time in hours, lag $=$ lag time in hours and $g=$ growth rate in divisions $\mathrm{h}^{-1}$. True lag times were determined from c.f.u. 
data by plating out dilutions of samples on LB agar in intervals of 30-60 min.

Characterization of active compounds. Acid and alkali sensitivity were determined by adding $\mathrm{HCl}$ or $\mathrm{NaOH}$, respectively, and keeping the treated samples at $\mathrm{pH} 4 \cdot 2$ or $12 \cdot 8$, respectively, for $45 \mathrm{~min}$ at $25^{\circ} \mathrm{C}$, after which the $\mathrm{pH}$ was readjusted to $\mathrm{pH} 7$ with $\mathrm{NaOH}$ or $\mathrm{HCl}$. Proteinase sensitivity was tested by incubating samples with 2 and $10 \mathrm{mg}$ Proteinase $\mathrm{K}$-acrylic beads (Sigma) $\mathrm{ml}^{-1}$ for 30 and $60 \mathrm{~min}$ at $37^{\circ} \mathrm{C}$.

Dialysis was performed against distilled water for $20 \mathrm{~h}$ at $25^{\circ} \mathrm{C}$ using either standard dialysis tubing or SpectraPor 3 membrane ( $3.5 \mathrm{~K}$ cut-off). Ion-exchange affinity was tested by employing DE52 and CM52 resins (Whatman) at $4 \mathrm{~g}(\mathrm{ml}$ supernatant $)^{-1}$ for $20 \mathrm{~min}$ at $\mathrm{pH} 4,7$ or 10 at $25^{\circ} \mathrm{C}$. Residues of the resins were removed by centrifugation $(4000 \mathrm{~g}, 10 \mathrm{~min})$ and filtration through $0.22 \mu \mathrm{m}$ cellulose acetate membrane filters (Sartorius).

Preparation of extracts. Salts were removed from sterile filtered supernatants by consecutive ion-exchange treatment with DE52 and CM52 at pH 7 (see above) and the treated supernatants were evaporated to dryness at $60^{\circ} \mathrm{C}$ using a rotary evaporator. Extracts were resuspended in 1/60 volume of distilled water, and frozen at $-20^{\circ} \mathrm{C}$. The extracts obtained by this procedure are referred to as 'supernatant concentrates' in this study.

Ethyl acetate extractions of supernatants were performed at $\mathrm{pH} 4 \cdot 7,7$ and 9.6, the solvent was evaporated, and the extracts were resuspended in HPLC grade water. Ethanol extracts were performed after saturation of supernatants with $\mathrm{K}_{2} \mathrm{CO}_{3}$ $\left(0 \cdot 9 \mathrm{~g} \mathrm{ml}^{-1}\right)$, employing three times equal volumes of HPLC grade ethanol. The ethanol was evaporated off, the extracts were resuspended in HPLC grade water, and the extraction was repeated twice. This procedure allows effective removal of salts and concentration of up to 300 -fold.

Analysis of supernatant extracts by HPLC and LC-MS. Supernatant concentrates and extracts were separated by HPLC (Waters 2690) employing a variety of columns and solvents. The columns used included reverse-phase columns such as Sphereclone C18 (Phenomenex), Symmetry C18 (Waters) and Supelcosil LC18S (all $5 \mu \mathrm{m}, 3.5 \times 150 \mathrm{~mm}$ ), a normal phase column (NOVAPAK Silica; Waters), a phenyl column (NOVAPAK Phenyl) and a size-exclusion column (Ultrahydrogel 120; Waters). Solvent systems were mixtures of HPLC grade water with either $0.5 \mathrm{mM}$ acetic acid or $3 \mathrm{mM}$ ammonium acetate, and with varying concentration of methanol or acetonitrile. Separation was performed at $30^{\circ} \mathrm{C}$, and elution was monitored using a diode-array detector. Fractions were taken every 0.5-1 min, evaporated, resuspended in HPLC grade water, and tested for activity. Electrospray MS (LCT instrument; Micromass) was performed either on active fractions directly (by using a syringe pump at $5 \mu \mathrm{min}^{-1}$ ) or by linking the HPLC directly to the LC-MS interface.

\section{RESULTS}

\section{Effects of the addition of stationary phase supernatants to cultures of $E$. coli}

Batch cultures of E. coli strains were grown in $\mathrm{MM}$ medium containing $0.04 \%(\mathrm{w} / \mathrm{v})$ glucose at $37^{\circ} \mathrm{C}$ with shaking. Cultures reached a final cell density of between $7 \times 10^{8}$ and $1.5 \times 10^{9}$ c.f.u. $\mathrm{ml}^{-1}$, and were kept at the same temperature with further shaking. Cells of E. coli ATCC 25922 were kept in stationary phase for $2 \mathrm{~d}$, at

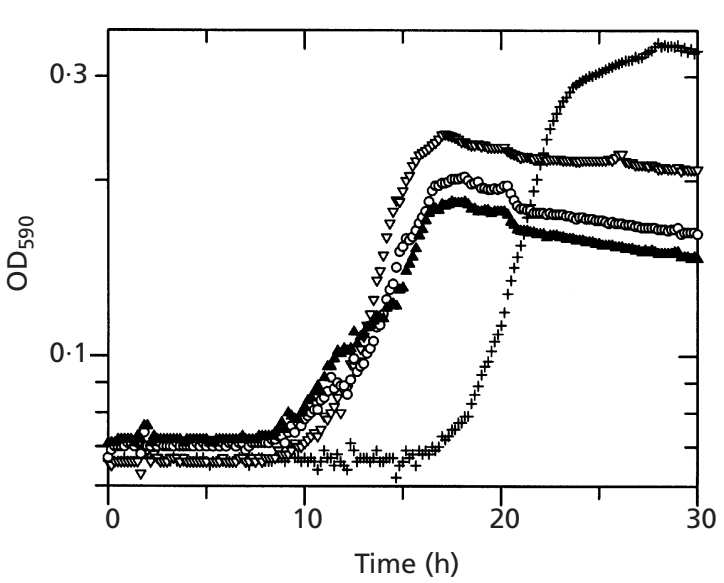

Fig. 1. Addition of untreated supernatant during recovery of starved cells of $E$. coli ZK126. Cells starved in MM medium for $53 \mathrm{~d}$ were diluted (to a final density of 144 c.f.u. $\mathrm{ml}^{-1}$ ) in fully supplemented MM medium (containing $0.04 \%, w / v$, glucose) amended with different amounts of supernatants of a culture of the same strain that had been starved for $2 \mathrm{~d}$ under identical conditions (see Methods; + , control; $\nabla$, addition of $30 \%$ untreated supernatant; $O, 50 \%$ supernatant; $\boldsymbol{\Delta}, 80 \%$ supernatant). Datasets shown are representative sets of five parallel sets each.

which time the cell density was $1 \cdot 3 \times 10^{9}$ c.f.u. $\mathrm{ml}^{-1}$. When these cells were diluted in fresh growth medium to a final cell density of 284 c.f.u. $\mathrm{ml}^{-1}$, their recovery was strongly stimulated by addition of supernatant of $2-\mathrm{d}-$ old stationary phase cells of the same strain. The apparent lag times (as estimated from BioScreen $\mathrm{OD}_{590}$ data) of unamended stationary phase cells were $20 \cdot 3 \mathrm{~h}$ (all data means of five experiments; $\mathrm{SD}=1 \cdot 51$ ), while the same cultures amended with $30 \%(\mathrm{v} / \mathrm{v})$ filtered supernatant displayed lag times of only $13 \cdot 2 \mathrm{~h} \quad(\mathrm{SD}=$ $0 \cdot 44)$. Cells of the same strain in the exponential phase of growth (at $4.05 \times 10^{8}$ c.f.u. $\mathrm{ml}^{-1}$, diluted to a final cell density of 560 c.f.u. $\mathrm{ml}^{-1}$ ) were also stimulated by the addition of stationary phase cell supernatant. Untreated growing cell populations showed mean lag times of $10 \cdot 9 \mathrm{~h}(\mathrm{sD}=0 \cdot 22)$, while populations treated with $30 \%$ $(\mathrm{v} / \mathrm{v})$ of the same supernatant as employed above were observed to display an apparent lag of $8 \cdot 5 \mathrm{~h}(\mathrm{SD}=0 \cdot 21)$. In summary, stimulation of recovery by supernatant addition was observed reproducibly with growing or starving cells, but stimulation of stationary phase cells was much more pronounced than that of growing cells of the same strain in the same medium.

A detailed analysis of supernatant effects on stationary phase cells is shown in Fig. 1. Here cells of E. coli ZK126 that had been carbon-starved for $53 \mathrm{~d}$ were diluted in fresh, fully supplemented MM medium (with $0.04 \%$, $\mathrm{w} / \mathrm{v}$, glucose) to a final density of 144 c.f.u. $\mathrm{ml}^{-1}$. The apparent lag times of the diluted cells ranged from 16 to $20 \mathrm{~h}$ (mean of 10 parallels : $17 \cdot 9 \mathrm{~h}$ ). Addition of supernatant from a culture of the same strain that had been starved under identical conditions for $2 \mathrm{~d}(1 \times$ $10^{9}$ c.f.u. $\mathrm{ml}^{-1}$ ) reduced lag times in a dose-dependent 
fashion (Fig. 1). The mean apparent lag time in the presence of $80 \%(\mathrm{v} / \mathrm{v})$ supernatant was determined to be $8.5 \mathrm{~h}$. At the same supernatant concentration, the mean growth rates and yields, however, were also reduced from 0.26 to $0 \cdot 1$ (apparent) divisions $\mathrm{h}^{-1}$, and from a final $\mathrm{OD}_{590}$ of $0 \cdot 38$ to $0 \cdot 17$, respectively, as deduced from the data obtained using the BioScreen (see Fig. 1). The variation in the lag phase was also reduced significantly by the presence of supernatant. In one experiment, the variation of lag phase duration expressed as $\%$ of the mean value of 10 parallel experiments was reduced from $11 \cdot 3$ to $4 \cdot 1 \%$ by addition of $15 \%(\mathrm{v} / \mathrm{v})$ supernatant, and to $0.7 \%$ by addition of $33 \% \quad(\mathrm{v} / \mathrm{v})$ supernatant (data not shown). In other experiments, a reduction of variation by supernatant addition was always observed, although in some cases it was less pronounced (see data described above). Similar results were obtained with all three E. coli strains tested: supernatants of the strains ZK126, ZK1000 and ATCC 25922 stimulated recovery of stationary phase cells of all three strains (data not shown). Thus the effect, and the production of stimulatory material, was not restricted to one strain of E. coli.

\section{Influence of growth conditions on stimulation by supernatant}

The reduction of lag phases was observed reproducibly both when the cells were allowed to enter stationary phase due to depletion of glucose, as in the experiments described above, or when cells were harvested and resuspended in MM medium lacking a carbon source, and kept for the same time as the glucose-depleted cells (see Methods, data not shown). Cell populations that were growth-limited due to depletion of a nitrogen or phosphorus source in the presence of an excess of carbon $(0.8 \%, \mathrm{w} / \mathrm{v}$, glucose $)$ were also tested concerning both susceptibility to growth stimulation and the production of growth-stimulating substances. Nitrogen and phosphorus limitation were achieved by setting the concentration of $\mathrm{NH}_{4} \mathrm{Cl}$ and $\mathrm{K}_{2} \mathrm{HPO}_{4}$ to 2.64 and $0.44 \mathrm{mM}$, respectively; the resulting final cell densities were $1.83 \times 10^{9}$ and $1.17 \times 10^{9}$ c.f.u. $\mathrm{ml}^{-1}$, respectively. Significant reduction of lag phases was observed in either case (data not shown). Stationary phase cells of ATCC 25922 were also tested after growth on $0.05 \%$ $(\mathrm{w} / \mathrm{v})$ glycerol or succinate as sole source of carbon. In both cases, addition of supernatant obtained from a carbon-starved culture of the same strain grown on glucose (as described above) significantly shortened the lag phases. Supernatants obtained from 2-d-old stationary phase cultures grown on glycerol or succinate also reduced the lag phases of glucose-depleted cells to a similar extent as the supernatants of cells grown on glucose (data not shown). No stimulation or inhibition could be observed when cells were grown in rich, complex media: stationary phase cells that had grown in Luria broth $\left(5 \mathrm{~g} \mathrm{NaCl}^{-1}\right)$ or MOPS-buffered Luria broth (with added $40 \mathrm{mM}$ MOPS) grew equally fast in the presence or absence of $10 \%(\mathrm{v} / \mathrm{v})$ supernatant from the same culture.

\section{Influence of density and age of cell populations on activity of supernatants}

As expected, the density of supernatant-producing cultures (dependent on the concentration of glucose added at the onset of the experiment) had some influence on the effects of the supernatants. The supernatants obtained from a high-density culture of ZK126 (MM medium with $0.4 \%, \mathrm{w} / \mathrm{v}$, glucose; $4 \times 10^{9}$ c.f.u. $\mathrm{ml}^{-1}$ ) had a stronger stimulatory effect than that of a culture with fivefold lower cell density $(0.04 \%, \mathrm{w} / \mathrm{v}$, glucose; $8 \times 10^{8}$ c.f.u. $\mathrm{ml}^{-1}$ ). In one experiment with recovering stationary phase cells of ZK126, the untreated control cells showed mean apparent lag times of $17 \cdot 2 \mathrm{~h}$. Here, the addition of $30 \%(\mathrm{v} / \mathrm{v})$ high-density supernatants reduced lag times to $11 \cdot 1 \mathrm{~h}$, and addition of the same proportion of low-density supernatant led to lag times of $13.8 \mathrm{~h}$ (all data means of five experiments each; similar results were obtained with ATCC 25922).

The effect of the age of cell populations on the stimulatory activity of their supernatants was tested in a series of experiments. In one set of experiments, populations of exponentially growing cells of E. coli ZK126 were harvested at $3.75 \times 10^{8}$ c.f.u. $\mathrm{ml}^{-1}$, and 2-dold stationary cells of the same strain were harvested at $8.5 \times 10^{8}$ c.f.u. $\mathrm{ml}^{-1}$, and the supernatants obtained were sterile filtered. In parallel experiments, the two supernatant preparations were added at the same concentrations to 2-d-old stationary phase cells of the same strain (cell density $9 \cdot 1 \times 10^{8}$ c.f.u. $\mathrm{ml}^{-1}$ ) diluted in fresh MM medium to a final density of 120 c.f.u. $\mathrm{ml}^{-1}$. Both supernatants significantly shortened the lag times of the recovering cells, but the supernatant of stationary phase cells clearly had a stronger effect than that of growing cells. Exponential phase supernatant shortened the apparent lag times from $17 \cdot 2 \mathrm{~h}$ (untreated cells, SD $=$ $0 \cdot 47, n=5$ in all experiments $)$ to $14.9 \mathrm{~h}(\mathrm{sD}=0 \cdot 39)$ when added at $15 \%(\mathrm{v} / \mathrm{v})$, and to $13.4 \mathrm{~h}(\mathrm{sD}=0.25)$ when added at $30 \%(\mathrm{v} / \mathrm{v})$. Stationary phase supernatants, on the other hand, reduced the apparent lag times of the same population of recovering cells to $12.8 \mathrm{~h}$ $(\mathrm{sD}=0.26)$ when added at $15 \%(\mathrm{v} / \mathrm{v})$, and to $11.5 \mathrm{~h}$ $(\mathrm{sD}=0 \cdot 21)$ when added at $30 \%(\mathrm{v} / \mathrm{v})$. Supernatants of cell populations kept in stationary phase for 3 or more days showed similar levels of activity as those kept for $2 \mathrm{~d}$ (data not shown). Thus for simplicity a standard time of $2 \mathrm{~d}$ of stationary phase (exactly $40 \mathrm{~h}$ ) was adopted prior to harvesting for supernatant production.

\section{Effect of supernatant addition on true lag times}

True lag times were determined by plating on LB agar at intervals of 30-60 min. After $2 \mathrm{~d}$ in stationary phase, the mean true lag time displayed by populations of $E$. coli ZK126 was $2 \cdot 2 \mathrm{~h}$ (mean of triplicates). After $8 \mathrm{~d}$ in stationary phase, populations of equal density were observed to have a mean lag phase of $4.5 \mathrm{~h}$, after $48 \mathrm{~d}$ $5.5 \mathrm{~h}$, and after $138 \mathrm{~d} 5.6 \mathrm{~h}$ (means of triplicates). Interestingly, the c.f.u. counts were observed to drop transiently during the lag phase of recovering cells which had been kept in stationary phase for 48 or more days. 
The decreases were between 20 and $85 \%$ of the initial c.f.u. counts, with the lowest counts observed between 3 and $5 \mathrm{~h}$ after dilution in fresh medium. When $30 \%(\mathrm{v} / \mathrm{v})$ supernatant was added to 2 -d-old stationary cells, true lag times were reduced to $1 \cdot 3 \mathrm{~h}$ (data not shown). When 138-d-old cells were diluted in fresh medium (final cell density of 275 c.f.u. $\mathrm{ml}^{-1}$ ) amended with supernatant extract (corresponding to addition of $30 \%, \mathrm{v} / \mathrm{v}$, supernatant), the true lag times were found to be between $1 \cdot 8$ and $2.5 \mathrm{~h}$ (data not shown). When supernatants or supernatant extracts were present during recovery, a decrease of c.f.u. counts such as described above for untreated suspensions was never observed. Growth rates were also increased by a factor of 1.5 in the presence of supernatant components. Corrected for the decrease in generation time, this reduction in lag time by supernatant addition amounts to $58-62 \%$ of the lag time in unsupplemented media. Thus addition of supernatant concentrate led to a significant reduction not only of the apparent lag times (as measured by using the BioScreen), but also of the true lag times, as determined by colony counts.

\section{Assessment of the number of recovering cells}

The number of recovering cells in the presence and absence of supernatant was tested using an MPN (most probable number) technique: serial dilutions of stationary phase cells of ATCC 25922 or ZK126 were inoculated into fresh media with or without $30 \%$ (v/v) addition of the supernatant of a $2 \mathrm{~d}$ stationary phase culture of ATCC 25922. Ten parallels were employed for each treatment, and growth was monitored over $10 \mathrm{~d}$ using the BioScreen growth analyser (with $\mathrm{OD}_{590}$ recorded every hour). No difference, however, was observed between MPN estimates of the recovery of treated and untreated samples in either of the strains: the percentages of replicate cultures that had grown were identical in the presence or absence of supernatant (data not shown). Thus we conclude that the components present in supernatants do not increase the number of recovering cells, but merely accelerate their recovery and subsequent growth.

\section{Characterization and extraction of the active compound(s)}

It was found that the growth-stimulating compound(s) produced by E. coli ATCC 25922 and ZK126 was preserved after $30 \mathrm{~min}$ boiling (Fig. 2, data shown for ATCC 25922 only). Further, the activity was found to be acid- and alkali-stable: exposure to $\mathrm{pH} 4 \cdot 2$ or $12 \cdot 8$ (at $25^{\circ} \mathrm{C}$ ) for $45 \mathrm{~min}$ each did not reduce the activity. Also, treatment with proteinase $\mathrm{K}$ (see Methods) had no effect on the growth-stimulating component (data not shown). Hence, the active component is heat-, acid-, alkali- and proteinase-resistant. On the other hand, heating to $250{ }^{\circ} \mathrm{C}$ for $17 \mathrm{~h}$ destroyed the activity completely (data not shown). Dialysis quantitatively removed the active constituents from supernatants: dialysed supernatant had no stimulatory activity whatsoever - in fact,

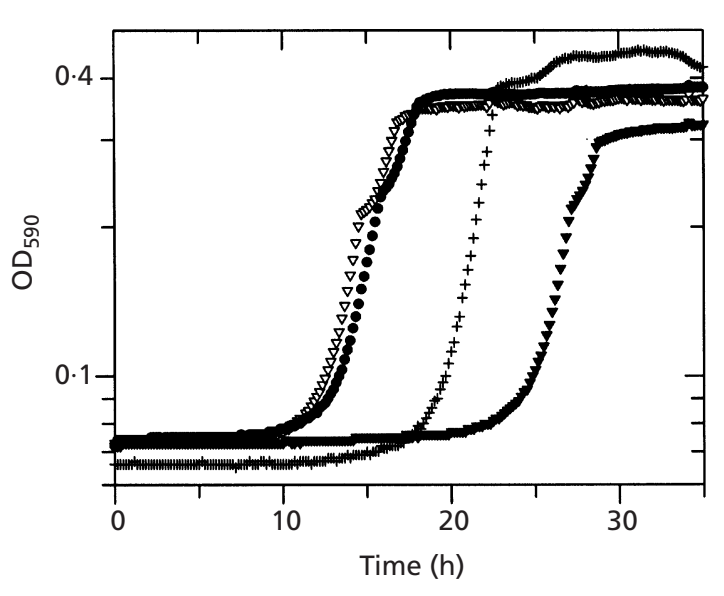

Fig. 2. Addition of untreated, heated $\left(30 \mathrm{~min}\right.$ at $100^{\circ} \mathrm{C}$ ) and dialysed $(20 \mathrm{~h})$ supernatant from a carbon-starved culture of E. coli ATCC 25922 to recovering cells of the same strain (see Methods). +, Control; O, addition of $50 \%$ untreated supernatant; $\nabla, 50 \%$ heated supernatant; $\nabla, 50 \%$ dialysed supernatant. Datasets shown are representative sets of five parallel sets each.

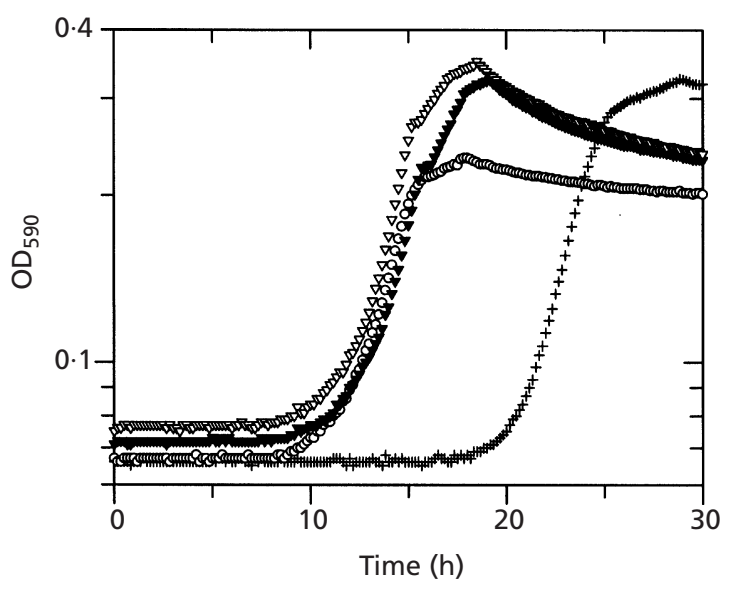

Fig. 3. Effect of ion-exchange treatment on the activity of supernatant from a carbon-starved culture of E. coli ZK126 to recovering cells of the same strain (see Methods). Datasets shown are representative sets of five parallel sets each. +, Control; $O$, addition of $30 \%$ untreated supernatant; $\nabla$, addition of $30 \%$ supernatant treated with ion-exchange resins DE52 and CM52; $\nabla$, addition of concentrate of treated supernatant, corresponding to $30 \%$ supernatant addition.

significant inhibitory effects were observed after addition of dialysed supernatants (Fig. 2). Identical results were obtained for supernatants and cells of E. coli ATCC 25922 and ZK126.

Ion-exchange resins DE52 and CM52 were not found to retain significant amounts of active material at $\mathrm{pH} 4,7$ or 10. In fact, inhibitory material was removed by consecutive treatment with both ion-exchange resins (at neutral $\mathrm{pH}$ and $25^{\circ} \mathrm{C}$ ), allowing growth to higher final cell densities as compared to growth in the presence of untreated supernatant (Fig. 3). Activity was also main- 


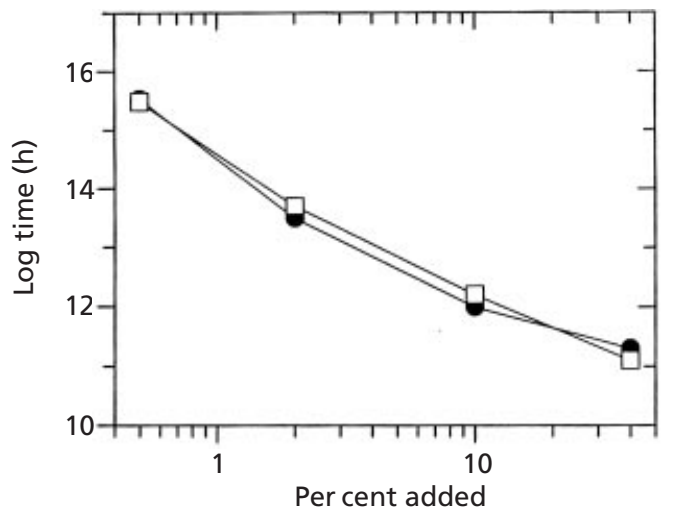

Fig. 4. Extraction of active components with ethanol. Raw supernatants of E. coli ZK126 were added at concentrations of between 0.5 and $40 \%(\%)$, and ethanol extracts from the same supernatants were added in amounts equivalent to those concentrations $(\square)$. Lag times (of stationary phase cells of $E$. coli ZK126 after dilution to a final cell density of 236 c.f.u. $\mathrm{ml}^{-1}$ ) were estimated by curve fitting the $\mathrm{OD}_{590}$ data obtained from BioScreen readings (see Methods), and the resulting apparent lag times shown are means of five parallels. Untreated cells displayed an apparent lag time of $17 \mathrm{~h}$ (mean of 20 parallels).

tained during rotary evaporation of supernatants or extracts (Fig. 3), which allowed concentration of samples up to 80 -fold.

Extraction with ethyl acetate was not successful: no activity was detected in the organic phase after extraction at any $\mathrm{pH}$ tested (see Methods), while more than $95 \%$ of the activity remained in the aqueous phase even after several consecutive extractions with the solvent (data not shown).

After saturation with salt, the active component(s) could be recovered by extraction with ethanol (as outlined in Methods). Quantitative recovery could be demonstrated after three rounds of extraction (Fig. 4). Thus ethanol extraction of carbonate-saturated supernatants was shown to be a convenient and elegant way of concentrating the active compound(s).

HPLC was used as described in Methods to separate substances present in supernatant concentrates and ethanol extracts. More than 20 substances could be detected using the diode-array detector: uracil, cytosine, xanthine and thymine were tentatively identified by LCMS to be present in the extracts. Stimulatory activity comigrated with the uracil peak, irrespective of the type of column employed. Uracil, however, was shown not to be active (see below), and no other reproducible peak correlating with activity could be detected by LC-MS. A range of conditions (flow rates, solvents, voltages, etc.) was tested, but none of these attempts proved successful for identifying the active substance chemically.

\section{Testing vitamins and other growth factors}

In order to test the possibility that the supernatant components affording the growth stimulation are vitamins or other growth factors, a complete set of

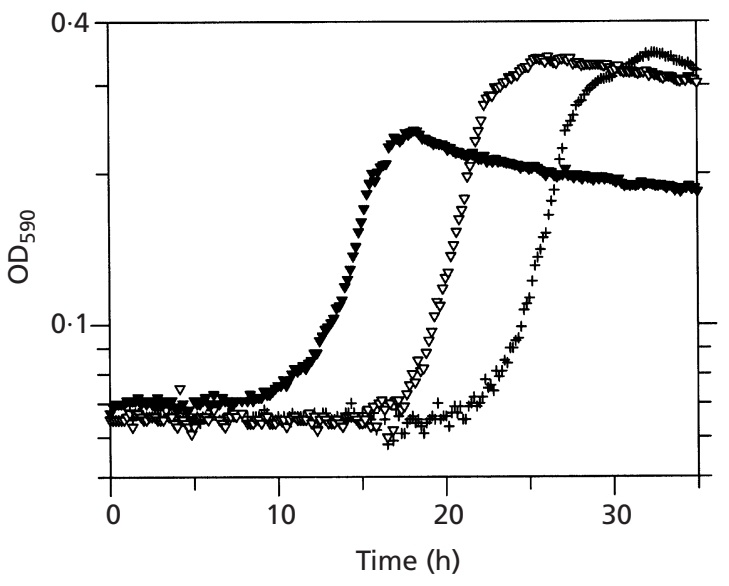

Fig. 5. Effect of addition of vitamins or supernatant. Stationary phase cells of $E$. coli ZK126 which had been kept at $37{ }^{\circ} \mathrm{C}$ for $45 \mathrm{~d}\left(5.7 \times 10^{6}\right.$ c.f.u. $\left.\mathrm{ml}^{-1}\right)$ were diluted with fresh medium to a density of 113 c.f.u. $\mathrm{ml}^{-1}$. The diluent was either untreated media $(+)$, or medium amended with $30 \%$ supernatant of the same strain (heat-treated for $20 \mathrm{~min} ; \boldsymbol{\nabla}$ ), or amended with a set of 12 vitamins $(\nabla)$ (see Methods).

vitamins, a set of purines and pyrimidines, and a selection of amino acids were tested in their effect on recovery and growth.

A complete set of 12 vitamins, as detailed in Methods, stimulated growth to a certain extent, but not as much as brought about by supernatant addition. This was observed for cells that had been in stationary phase for 2 or $45 \mathrm{~d}$ for both strains tested (ZK126 and ATCC 25922; data shown for ZK126 in Fig. 5). Addition of thiamin at a range of concentrations (see Methods), in addition to the set of 12 vitamins, had no further effect on lag times or growth rates, and thiamin addition alone had no effect on lag times (data not shown).

As expected, addition of yeast extract or Casamino acids (both at $0.03-0.0003 \%, \mathrm{w} / \mathrm{v}$ ) allowed recovery to proceed much faster than in the untreated controls. Supplementation with yeast extract or Casamino acids at concentrations of $0.003 \%(\mathrm{w} / \mathrm{v})$ or more led to faster recovery than in the basal media amended with $30 \%$ $(\mathrm{v} / \mathrm{v})$ supernatants (data not shown). None of the single amino acids tested (methionine, threonine, leucine, isoleucine and glutamate), however, could be shown to be responsible for growth stimulation. None of the following substances stimulated recovery of stationary phase E. coli: sodium acetate, fumarate, L-homoserine lactone, L-homoserine, DL-homocysteine, butyrylhomoserine lactone (BHL) and $\mathrm{N}$-hexanoylhomoserine lactone (HHL), and glutathione (disodium salt). Amino acids were tested at concentrations between $1 \mu \mathrm{M}$ and $1 \mathrm{mM}$, sodium acetate was tested at concentrations ranging from 0.0001 to $1 \%(\mathrm{w} / \mathrm{v})$, fumarate at between 0.01 and $0.5 \%(\mathrm{w} / \mathrm{v}), \mathrm{L}-\mathrm{homoserine}$ lactone was tested at between 0.2 and $500 \mu \mathrm{M}, \mathrm{L}$-homoserine and DLhomocysteine at between $0 \cdot 2$ and $10 \mu \mathrm{M}$, BHL and HHL from 0.1 to $100 \mu \mathrm{M}$, and glutathione from 0.01 to $0.5 \%$ (w/v) (ZK126 tested only, data not shown). Addition of 
reduced and oxidized forms of glutathione (added from freshly prepared stock solutions) did not reduce lag times of stationary phase cells of E. coli ZK126 at concentrations between 0.01 and $0.5 \%(\mathrm{w} / \mathrm{v})$, but rather had dose-dependent inhibitory effects. Also, addition of noradrenaline (Arterenol, bitartrate salt; Sigma A9512) at a concentration of $50 \mu \mathrm{M}$ (as described by Lyte $e$ al., 1996) did not lead to a reduction, but to an increase of the lag times observed in our assays with ZK126 (data not shown).

Due to the presence of purines and pyrimidines in supernatant extracts and the stability of active compounds (see above), purines and pyrimidines and their heat-stable derivatives were screened employing HPLC and BioScreen assays. The reverse-phase HPLC retention times of the following chemicals were much longer than those of the active fractions, and were thus not tested further: 1-methyl-adenine, 2-O-methyladenine, 3-O-methyl-adenine, ${ }^{6} \mathrm{~N}$-methyl-adenine, adenosine, adenosine-monophosphate, adenosine- $5^{\prime}$ diphosphate, adenosine-2',5'-diphosphate, $\mathrm{P}^{1}, \mathrm{P}^{2}$ di (adenosine- $\left.5^{\prime}\right)$-pyrophosphate, $\mathrm{P}^{1}, \mathrm{P}^{4}$-di(adenosine- $\left.5^{\prime}\right)$ tetraphosphate, $S$-adenosyl-methionine, cytosine, isocytosine, guanosine, cGMP, thymine, 1-methyl-uracil, 3-methyl-uracil, 6-methyl-uracil, 5-ethyl-uracil, uracil4-acetic acid and the cyclic dipeptides (diketopiperazines) cyclo-(Phe-Ser), cyclo-(His-Pro) and cyclo(His-Phe). Of all the chemicals tested, only uracil and 5hydroxy-methyl-uracil displayed HPLC retention times similar to those of the active substance(s). Uracil and 5hydroxy-methyl-uracil, however, were without effect on recovery of E. coli ZK126 or ATCC 25922 when applied between $0 \cdot 2$ and $770 \mu \mathrm{g} \mathrm{ml}^{-1}$ (data not shown). Adenine, guanine, xanthine, cAMP or GTP also had no stimulatory effect on starved cells at between 0.1 and $10 \mu \mathrm{g} \mathrm{ml}^{-1}$. In short, none of the pure chemicals tested could mimic the effect of supernatant products.

\section{Testing the presence of nutrients or siderophores in supernatants}

To test for the presence of nutrients in the supernatants and extracts, strain ZK126 was grown in MM medium containing $0.04 \%(\mathrm{w} / \mathrm{v})$ glucose for $16 \mathrm{~h}$ and then diluted 1:500 in MM medium with either limiting nitrogen source $\left(0.49 \mathrm{mM} \mathrm{NH}_{4} \mathrm{Cl}\right.$ and $0.5 \%, \mathrm{w} / \mathrm{v}$, glucose) or limiting carbon source $\left(9.5 \mathrm{mM} \mathrm{NH}_{4} \mathrm{Cl}\right.$ and $0.015 \%, \mathrm{w} / \mathrm{v}$, glucose). The final cell densities of the cultures were $2.02 \times 10^{8}$ and $2.34 \times 10^{8}$ c.f.u. $\mathrm{ml}^{-1}$, respectively. These cultures were then split into aliquots, one-half of which were amended with supernatants, supernatant extracts, or active fractions from HPLC at concentrations corresponding to those which had previously been shown to yield stimulation. Other media ingredients such as fresh nutrients were not added in this set of experiments, in order to test whether supernatant extracts themselves could supply carbon or nitrogen sources. During the following incubation at $37^{\circ} \mathrm{C}$, $\mathrm{OD}_{590}$ and c.f.u. were monitored, and the experiment was repeated at least five times with each treatment. Upon addition of supernatant extracts or active fractions, the $\mathrm{OD}_{590}$ was observed to increase slightly immediately in comparison to the control. In carbonlimited cultures, the $\mathrm{OD}_{590}$ in the amended samples was $0 \cdot 168$ as compared to 0.164 (means of 12 measurements; standard deviations 0.017 and 0.016 , respectively), and in nitrogen-limited cultures $0 \cdot 184$ as opposed to $0 \cdot 177$ (means of 11 experiments; standard deviations 0.022 in both cases). When the $\mathrm{OD}_{590}$ measurements were extended over $4 \mathrm{~h}$, no further increases were observed. The c.f.u. counts in the treated cultures, however, were not higher than in the untreated cultures in any experiment at any time (samples were taken 40 and 170 min after addition) - actually, carbon-limited cultures displayed significantly lowered c.f.u. counts after supernatant extracts had been added, while nitrogen-limited cultures were unaffected $(P<0 \cdot 05)$. In short, no growth of carbon- or nitrogen-limited cultures could be observed by addition of supernatant or supernatant extracts at concentrations which elicit the stimulation of growth described above. The slightly elevated $\mathrm{OD}_{590}$ data in treated samples can be explained by light absorption of the extracts themselves or by slight modification of the refractive index of the cells which is largely responsible for the light scattering in measurements of this type (Davey \& Kell, 1996).

A series of experiments was performed in order to test the hypothesis that siderophore production might be responsible for the stimulatory activity of supernatants. To this end, the effect of supernatants of iron-limited cells on recovery was tested. Stationary phase cells (ZK126 grown overnight in fully supplemented MM medium with $0.04 \%, \mathrm{w} / \mathrm{v}$, glucose) were diluted $(1: 100)$ in MM medium not amended with iron (with $0.04 \%$ glucose), and growth was allowed to proceed into stationary phase as in the standard experiments. The addition of the supernatants of these (iron-starved) cells, however, had a smaller effect on lag times of recovering E. coli ZK126 than supernatants from fully supplemented cells of the strain. Also, neither excess addition of $\mathrm{FeSO}_{4}(20$ or $50 \mu \mathrm{M})$ nor addition of 2,3-dihydroxybenzoate $(2-100 \mu \mathrm{M})$ had any effect on lag times of recovering cells (strains ATCC 25922 and ZK126 tested). Thus siderophore production can be excluded as an explanation for the autostimulatory effect.

\section{DISCUSSION}

In eukaryotes, cellular growth, behaviour and survival are known to be highly dependent on extracellular signals excreted by surrounding cells (Christensen et al., 1998; Raff, 1992). Recently, such social phenomena are becoming more and more evident in a variety of aspects of prokaryote biology. Productivity and virulence of bacteria are now in many cases recognized to be subject to social control (Fuqua \& Greenberg, 1998; Kaiser \& Losick, 1993; Salmond et al., 1995; Swift et al., 1994). Growth and survival of prokaryotes, however, are still considered to be largely independent of the presence of sister cells. In this sense, the concept has persisted that microbial cells are independent units interacting mainly through means of competition and antibiosis. There are 
many observations, though, which indicate that this concept is only partly true, and that indeed bacterial cells under certain conditions require the presence of sister cells (or products excreted by them) for growth and survival (Barer \& Harwood, 1999; Kaprelyants \& Kell, 1996; Kaprelyants et al., 1999; Kell et al., 1995). Publications on such observations are, however, relatively rare, and only in very few cases an explanation of these effects could be offered. For example, the lag times of cells aged for less than $8 \mathrm{~h}$ ('early lag') of Klebsiella aerogenes could be abolished by addition of filtrates from growing cells of the organism (Lodge \& Hinshelwood, 1943), but the identity of the active chemical(s) has not been elucidated. The lag times displayed by aged cells (older than $9 \mathrm{~h}$, and thus comparable to the aged cells employed in our study) could not be reduced by such addition (Lodge \& Hinshelwood, 1943). In one well-characterized case, Micrococcus luteus produces a peptide which acts as both a cytokine and pheromone: stationary phase cells of $M$. luteus produce a protein which dormant cells of the organism require for growth (Davey \& Kell, 1996; Kaprelyants \& Kell, 1993; Kaprelyants et al., 1994; Mukamolova et al., 1998a, b). Similar observations were made for aged cultures of Mycobacterium tuberculosis and other Mycobacterium species (Mukamolova et al., 1998a), and related molecules appear to be widespread among the actinomycetes (Kell \& Young, 2000).

In this paper, we report on the effects of the addition of spent medium on the regrowth of starved E. coli cells. Several phenomena could be observed: most strikingly, lag phases were strongly reduced by substances present in supernatants of stationary phase cells. Addition of raw supernatants at high concentrations, on the other hand, leads to inhibition of growth by reduction of growth rate and yield. A significant fraction of inhibitory material could be removed by ion-exchange treatment. Thus, the inhibitory effects are not merely a consequence of the lowered substrate concentration due to addition of supernatants, but a consequence of inhibitory products. The heat-labile inhibitory compound(s) might consist of peptides or proteins, and might constitute an inhibitory 'signal' excreted by the cells in stationary phase. These inhibitory compounds were, however, not characterized further, as the main aim of this study was to shed light on the stimulation of growth by excreted products.

\section{Stimulation of recovery of $E$. coli by supernatant addition}

Stationary phase cells of three strains of E. coli were shown to produce stimulatory substances, independent of the carbon source, the limiting nutrient or the age of cells. Susceptibility of cells to stimulation was also observed generally for all types of populations of the three strains tested, although stationary phase cells were stimulated more strongly than exponentially growing cells. Thus the production of and susceptibility to the stimulatory substance(s) are not restricted to specific strains or conditions. Preliminary screening of other bacterial species indicates that stationary phase cells of other Escherichia species (Escherichia vulneris, Escherichia fergusonii) and related species such as Salmonella typhimurium, Enterobacter cloacae, Klebsiella pneumoniae and Citrobacter freundii are stimulated significantly by supernatants obtained from stationary phase cells of E. coli ZK126 (data not shown). As the observed effect is not confined to the producer strain, any substance involved in the stimulation described here is not a true 'pheromone' as it is not species-specific.

In contrast to the events during resuscitation of Micrococcus luteus, growth of stationary phase cells of E. coli does not strictly require factors which are found in spent medium of the organism, because the number of recovering cells was independent of the presence of such factors. Hence the stimulation of growth of E. coli cells by supernatant addition is restricted to the reduction of lag times and increase in growth rates. Theoretically, such stimulation of growth could be brought about by amino acids, vitamins or similar nutritious material which could be leaking out of lysing cells. Our experiments with additions of supernatants or extracts to starving cells, however, did not reveal any potential role of this material as nutrient, because cells could not be observed to grow in the absence of added glucose. Also, it appears unlikely that nutritious substances would be present at significant concentrations in supernatants of stationary phase cultures grown in minimal medium, as the starving cells would be expected to be effective scavengers of these substances. Further, the chromatographic properties of the active principle were not similar to the above kinds of substance.

In our experiments, addition of supernatants or extracts of supernatants leads to significant shortening of lag phases of E. coli, particularly when the cells producing the substances and the cells tested were in prolonged stationary phase. This was observed both when apparent lag times (measured by optical density) or true lag times (monitored by c.f.u.) were determined during recovery. The discrepancies between apparent lag times and true lag times are simply a result of the sensitivity of the BioScreen growth analyser. We have determined that the lower limit of detection of the growth analyser for E. coli ZK126 and ATCC 25922 is $3 \times 10^{7}$ c.f.u. $\mathrm{ml}^{-1}$, which corresponds to an $\mathrm{OD}_{590}$ reading of 0.08 (blank readings with uninoculated MM medium gave readings between 0.065 and 0.07 ). Consequently, the first phases of recovery and growth of the diluted cultures (which have initial densities of $100-500$ c.f.u. $\mathrm{ml}^{-1}$ ) cannot be observed with the BioScreen. On the other hand, c.f.u. counts (which in our hands are sensitive down to 10 c.f.u. $\mathrm{ml}^{-1}$ ) can monitor the development of cell numbers throughout the lag phases in our experiments, well before the limit of detection of the BioScreen is reached. The BioScreen, however, is a reliable source of growth data such as apparent lag times and can be employed to screen many substances or fractions quickly, which is an impossible task when relying on c.f.u. determinations. 
The fact that the stimulatory effects of supernatants could not be observed when cells were grown in complex media is possibly due to a combination of the fact that the stimulatory compound is present in yeast extract and/or that lag times generally are minimal in the presence of a complete set of amino acids and vitamins. This is demonstrated by the fact that addition of yeast extract or Casamino acids at extremely low concentrations $(0.0003 \%, \mathrm{w} / \mathrm{v})$ shortened lag times of E. coli ZK126 significantly.

While untreated cell suspensions of freshly diluted stationary phase cultures displayed a slight decrease in c.f.u. during the lag phase, identical suspensions amended with supernatant components do not display this decrease. In theory, this effect could be indicative of the fact that a part of the population is transiently injured, and that this injury is avoided or alleviated in the presence of supernatant components. The fact, however, that the number of recovering cells in our experimental system is not influenced by the presence of supernatant components does not support this possibility. We conclude that substances present in the supernatants trigger or facilitate cell division during recovery, especially after prolonged stationary phase, rather than protect the cells from any deleterious effect of refeeding or dilution in fresh media. It is possible that a certain proportion of cells in all freshly diluted suspensions is (at least transiently) adversely affected by the process of handling and dilution. The discrepancy in the development of viable cells observed in the presence and absence of supernatant components might then merely be due to the fact that in the treated suspensions growth commences immediately, and thus compensates and occludes the decrease in c.f.u. in these samples. In summary, we hypothesize that E. coli produces a (or several) signal compound(s) or growth regulator(s) which stimulates (or stimulate) recovery from the stationary phase.

\section{Characterization of stimulatory substances in E. coli supernatants}

In order to elucidate the identity of the stimulatory compound, a range of chemicals was tested in their effect on lag times and growth rates. The chemicals were selected based on the possibility that they might be found in supernatants or that they might stimulate growth of E. coli. In the literature, several substances have been reported to be secretion products of the organism in the stationary phase. Amongst them are reduced glutathione (Loewen, 1979; Owens \& Hartman, 1986) and uracil, xanthine and hypoxanthine (Rinas et al., 1995). The presence of uracil and xanthine in stationary phase supernatants could be confirmed by electrospray MS. The autostimulatory activity, however, could not be duplicated by addition of any of these substances, alone or in combination, nor by any other chemicals tested. In particular, it was ascertained that a complete set of vitamins is not sufficient to mimic the supernatant effect on recovery. It is, however, possible that the autostimulatory substance constitutes a rare form of vitamin (or a combination of growth factors) which has not been included in the literature because it is not essential for growth.

So far, the active compound present in supernatants of E. coli has not been identified. To our knowledge, we have excluded all the substances that have been reported to be present in supernatants or which might stimulate growth significantly. Also, we have excluded a range of possible signal substances such as peptides or other ionic or zwitterionic substances (such as amino acids) by demonstrating activity in extracts after heat and proteinase treatment, or after ion-exchange treatment, respectively. Due to the lack of extraction in ethyl acetate, we believe that we have also excluded $N$ acylated homoserine lactones.

Unfortunately, no way of selectively extracting the active material could be found. Consequently it has not been possible to isolate large amounts of the active compound at high purity. The possibility remains that a mixture of substances is responsible for the growth stimulation observed. This is, however, unlikely because activity could be detected in a single fraction after several consecutive rounds of fractionation on different HPLC columns. The active material was found to comigrate with only two identifiable substances, namely uracil and 5-hydroxy-methyl-uracil; in fact, high levels of uracil could be detected in all supernatant extracts and in all active fractions. As stated above, however, no significant stimulation was observed after addition of uracil or 5-hydroxy-methyl-uracil. A range of other uracil derivatives and their isomers displayed HPLC retention times differing strongly from those of active fractions. No other substance could be identified in the active fractions, even when employing highly sensitive electrospray MS (LC-MS). Thus the chemical identity of the substance produced by E. coli, and stimulating stationary phase cells of itself and other bacteria, still remains to be elucidated. Given the large number of genes of unknown function in the $E$. coli genome (Blattner et al., 1997; Hinton, 1997), we may suppose that many more metabolites of this type will be identified.

\section{ACKNOWLEDGEMENTS}

We thank the BBSRC, under the aegis of the Celsis Connect programme, for financial support, and in particular Drs Peter Grant, Ray McKee and Brian Thomas of Celsis Ltd for their kind assistance. We are grateful to Dr Alun Jones (University of Wales, Aberystwyth) for the curve fitting programme, Jess Allen for experimental assistance, Jim Heald for mass spectrometry, and to Professors Gareth Morris and Michael Young (University of Wales, Aberystwyth), Colin Ratledge (University of Hull) and Tony Atkinson (Chimaeron Ltd) for many helpful discussions.

\section{REFERENCES}

Ajl, S. J. \& Werkman, C. H. (1948). Replacement of $\mathrm{CO}_{2}$ in heterotrophic metabolism. Arch Biochem 19, 483-492.

Baca-DeLancey, R. R., South, M. M., Ding, X. \& Rather, P. N. 
(1999). Escherichia coli genes regulated by cell-to-cell signaling. Proc Natl Acad Sci US A 96, 4610-4614.

Barer, M. R. \& Harwood, C. R. (1999). Bacterial viability and culturability. Adv Microb Physiol 41, 93-137.

Barrow, P. A., Lovell, M. A. \& Zhang Barber, L. (1996). Growth suppression in early-stationary-phase nutrient broth cultures of Salmonella typhimurium and Escherichia coli is genus specific and not regulated by $\sigma^{\mathrm{s}}$. J Bacteriol 178, 3072-3076.

Blattner, F. R., Plunkett, G., Bloch, C. A. \& 14 other authors (1997). The complete genome sequence of Escherichia coli K-12. Science 277, 1453-1462.

Christensen, S. T., Leick, V., Rasmussen, L. \& Wheatley, D. N. (1998). Signaling in unicellular eukaryotes. Int Rev Cytol 177, 181-253.

Connell, N., Han, Z., Moreno, F. \& Kolter, R. (1987). An Escherichia coli promoter induced by the cessation of growth. Mol Microbiol 1, 195-201.

Cote, R. J. \& Gherna, R. L. (1994). Nutrition and media. In Methods for General and Molecular Biology, pp. 155-178. Edited by P. Gerhardt. Washington, DC: American Society for Microbiology.

Davey, H. M. \& Kell, D. B. (1996). Flow cytometry and cell sorting of heterogeneous microbial populations: the importance of single cell analysis. Microbiol Rev 60, 641-696.

Dixon, N. M. \& Kell, D. B. (1989). The inhibition by $\mathrm{CO}_{2}$ of the growth and metabolism of microorganisms. J Appl Bacteriol 67, 109-136.

Freestone, P. P., Lyte, M., Neal, C. P., Maggs, A. F., Haigh, R. D. \& Williams, P. H. (2000). The mammalian neuroendocrine hormone norepinephrine supplies iron for bacterial growth in the presence of transferrin or lactoferrin. J Bacteriol 182, 6091-6098.

Fuqua, C. \& Greenberg, E. P. (1998). Self perception in bacteria: quorum sensing with acylated homoserine lactones. Curr Opin Microbiol 1, 183-189.

Fuqua, C., Winans, S. C. \& Greenberg, E. P. (1996). Census and consensus in bacterial ecosystems: the LuxR-LuxI family of quorum-sensing transcriptional regulators. Annu Rev Microbiol 50, 727-751.

Garcia-Lara, J., Shang, L. H. \& Rothfield, L. I. (1996). An extracellular factor regulates expression of sdiA, a transcriptional activator of cell division genes in Escherichia coli. J Bacteriol 178, 2742-2748.

Gray, K. M., Pearson, J. P., Downie, J. A., Boboye, B. E. A. \& Greenberg, E. P. (1996). Cell-to-cell signalling in the symbiotic nitrogen-fixing bacterium Rhizobium leguminosarum: autoinduction of a stationary phase and rhizosphere-expressed genes. J Bacteriol 178, 372-376.

Hinton, J. C. (1997). The Escherichia coli genome sequence: the end of an era or the start of the FUN ? Mol Microbiol 26, 417-422.

Holden, M. T., Ram Chhabra, S., de Nys, R. \& 14 other authors (1999). Quorum-sensing cross talk: isolation and chemical characterization of cyclic dipeptides from Pseudomonas aeruginosa and other Gram-negative bacteria. Mol Microbiol 33, 1254-1266.

Hull, W. E., Berkessel, A. \& Plaga, W. (1998). Structure elucidation and chemical synthesis of stigmolone, a novel type of prokaryotic pheromone. Proc Natl Acad Sci US A 95, 11268-11273.

Kaiser, D. \& Losick, R. (1993). How and why bacteria talk to each other. Cell 73, 873-885.

Kaprelyants, A. S. \& Kell, D. B. (1993). Dormancy in stationaryphase cultures of Micrococcus luteus: flow cytometric analysis of starvation and resuscitation. Appl Environ Microbiol 59, 3187-3196.

Kaprelyants, A. S. \& Kell, D. B. (1996). Do bacteria need to communicate with each other for growth? Trends Microbiol 4, 237-242.

Kaprelyants, A. S., Mukamolova, G. V. \& Kell, D. B. (1994). Estimation of dormant Micrococcus luteus cells by penicillin lysis and by resuscitation in cell-free spent culture medium at high dilution. FEMS Microbiol Lett 115, 347-352.

Kaprelyants, A. S., Mukamolova, G. V., Kormer, S. S., Weichart, D. H., Young, M. \& Kell, D. B. (1999). Intercellular signalling and the multiplication of prokaryotes: bacterial cytokines. Symp Soc Gen Microbiol 57, 33-69.

Kell, D. B. \& Young, M. (2000). Bacterial dormancy and culturability: the role of autocrine growth factors. Curr Opin Microbiol 3, 238-243.

Kell, D. B., Kaprelyants, A. S. \& Grafen, A. (1995). Pheromones, social behaviour and the functions of secondary metabolism in bacteria. TREE 10, 126-129.

Li, C., Wu, P. Y. \& Hsieh, M. (1997). Growth-phase-dependent transcriptional regulation of the $p c m$ and surE genes required for stationary-phase survival of Escherichia coli. Microbiology 143, 3513-3520.

Lodge, R. M. \& Hinshelwood, C. N. (1943). Physicochemical aspects of bacterial growth. Part IX. The lag phase of Bacteriol lactis aerogenes. J Chem Soc 213-219.

Loewen, P. C. (1979). Levels of glutathione in Escherichia coli. Can J Biochem 57, 107-111.

Lyte, M., Frank, C. D. \& Green, B. T. (1996). Production of an autoinducer of growth by norepinephrine cultured Escherichia coli O157-H7. FEMS Microbiol Lett 139, 155-159.

Mukamolova, G. V., Kaprelyants, A. S., Young, D. I., Young, M. \& Kell, D. B. (1998a). A bacterial cytokine. Proc Natl Acad Sci U S A 95, 8916-8921.

Mukamolova, G. V., Yanopolskaya, N. D., Kell, D. B. \& Kaprelyants, A. S. (1998b). On resuscitation from the dormant state of Micrococcus luteus. Antonie Leeuwenhoek 73, 237-243. Neidhardt, F., Bloch, P. L. \& Smith, D. F. (1974). Culture medium for Enterobacteriaceae. J Bacteriol 119, 736-747.

Owens, R. A. \& Hartman, P. E. (1986). Export of glutathione by some widely used Salmonella typhimurium and Escherichia coli species. J Bacteriol 168, 109-114.

Pesci, E. C., Milbank, J. B., Pearson, J. P., McKnight, S., Kende, A. S., Greenberg, E. P. \& Iglewski, B. H. (1999). Quinolone signaling in the cell-to-cell communication system of Pseudomonas aeruginosa. Proc Natl Acad Sci U S A 96, 11229-11234.

Raff, M. C. (1992). Social controls on cell survival and cell death. Nature 356, 397-400.

Rinas, U., Hellmuth, K., Kang, R., Seeger, A. \& Schlieker, H. (1995). Entry of Escherichia coli into stationary phase is indicated by endogenous and exogenous accumulation of nucleobases. Appl Environ Microbiol 61, 4147-4151.

Salmond, G. P. C., Bycroft, B. W., Stewart, G. S. A. B. \& Williams, P. (1995). The bacterial 'enigma': cracking the code of cell-cell communication. Mol Microbiol 16, 615-624.

Shapiro, J. A. (1998). Thinking about bacterial populations as multicellular organisms. Annu Rev Microbiol 52, 81-104.

Sitnikov, D. M., Schineller, J. B. \& Baldwin, T. O. (1996). Control of cell division in Escherichia coli: regulation of transcription of fts $Q A$ both involves RpoS and SdiA-mediated autoinduction. Proc Natl Acad Sci US A 93, 336-341. 
Srinivasan, S., Ostling, J., Charlton, T., DeNys, R., Takayama, K. \& Kjelleberg, S. (1998). Extracellular signal molecule(s) involved in the carbon starvation response of marine Vibrio sp. strain S14. J Bacteriol 180, 201-209.

Surette, M. G. \& Bassler, B. L. (1998). Quorum sensing in Escherichia coli and Salmonella typhimurium. Proc Natl Acad Sci US A 95, 7046-7050.

Surette, M. G., Miller, M. B. \& Bassler, B. L. (1999). Quorum sensing in Escherichia coli, Salmonella typhimurium, and Vibrio harveyi: a new family of genes responsible for autoinducer production. Proc Natl Acad Sci U S A 96, 1639-1644.

Swift, S., Bainton, N. J. \& Winson, M. K. (1994). Gram-negative bacterial communication by $\mathrm{N}$-acyl homoserine lactones: a universal language? Trends Microbiol 2, 193-198.

Swift, S., Throup, J. P., Williams, P., Salmond, G. P. C. \& Stewart, G. S. A. B. (1996). Quorum sensing: a population density component in the determination of bacterial phenotype. Trends Biochem Sci 21, 214-219.

Withers, H. L. \& Nordström, K. (1998). Quorum-sensing acts at initiation of chromosomal replication in Escherichia coli. Proc Natl Acad Sci U S A 95, 15694-15699.

Received 22 November 2000; revised 14 February 2001; accepted 26 February 2001. 